\title{
Challenges Facing the Integration of Physically Disabled Children in Regular Classrooms from the Perspective of Their Parents
}

\author{
Shama Yahaya Bader Al Hadid ${ }^{1, *}$ \\ ${ }^{1}$ The World Islamic Sciences \&Education University, Amman, Jordan \\ *Corresponding author: The World Islamic Sciences \&Education University, Amman, Jordan \\ Received: February 26, 2016 Accepted: May 23, 2016 Published: March 24, 2017 \\ doi:10.5296/ije.v9i1.10981ＵRL: https://doi.org/10.5296/ije.v9i1.10981
}

\begin{abstract}
The aim of this study is to find out the challenges facing the integration ofphysically disabled children in regular classrooms from the perspective of their parents, and to study the effect of educational level, gender, and the standard of living for the parents on their point of view. To achieve this purpose of this study, the researcher designed a questionnaire consisted of 20 paragraphs and distributed to parents of physically disabled students in the Governorate of Amman.

The sample of the study consisted of 196 parents of physically disabled students in the Governorate of Amman for the academic year 2013/2014 where a questionnaire was distributed to them.

To analyze the results, the researcher used the means and standard deviations. The results showed statically significant differences in the views of parents towards the integration of their physically disabled child in regular classrooms attributed to the educational level of the parents and in favor of parents with high school level or less.Alsothe results showed statically significant differences attributed to gender and in favor of females. Moreover, the results showed differences attributed to the level of living in favor of low-income people.

In accordance to results, the researcher provided some recommendations for researches, such as holding seminars to educate parents and introduce them to the importance of focusing on students with physical disabilities and the importance of integrating these students in regular classrooms.In addition to conduct further studies on a wider sample to include wider communities plus study other variables and their impact on the attitudes of parents.
\end{abstract}

Keywords: physically disabled students, integration, regular classrooms 


\section{Introduction}

The presence of physically disabled child in the family is considered a traumatic experience and this feeling of distress and frustration varies from a family to another. To start with, the family goes through psychological crisis, sadness, and anxiety at the birth of a physically disabled child, but with time the family copes with the new situation and accepts the disabled child and tries hard to meet the needs of this child and think of various ways to deal with him and provide the best care.

One of the challenges faced by parents is to try to integrate their disabled child with the community and his peers to help him overcome shyness. Various fields of education had witnessed great developments and achievements particularly in terms of schools in both curriculum and methods, or the mechanism of providing services for people with disabilities. It is worth noting what Rogers (Rogers) the founder of the humanitarian theory freedom of education where he called for "acceptance of the student as he is" which means starting with the student and not with the teacher which is considered a positive trend. He adds that accepting a student as he is carries aspects very important for the acceptance of a disabled child and recognizing their needs and put them in the priorities of family, school and society (Center of Education Studies 2000, CARE).

These major developments and achievements led to teach students with disabilities and integrate them in public education. In the last century, the negative perception towards disabledpeople changed into optimistic outlook based on the educational integration not isolation and segregation in private schools. Several modern studies confirmed that the disabled and particularly physical, hearing, visual, and mental disabilities enjoy the capabilities and possibilities that qualify them to integrate in public education with their normal peers. Integrating disabled students in general education at an early stage, helping them on the evolution of growth and this integration plays an active role in accepting them by other students and allows them to live in normal environment that is far from social isolation and loneliness (Al-Shakhes, 2004).

The impairment in social skills for children with physically disabilities must be raised where the children with physical disabilities form large proportion of the world, where the international institutions and bodies show the number of disabled children is on the rise and is concentrated mostly in developing countries (Waheed Al Sayed Hafeth, 2001).

Physically disabled children have special abilities and some are creative, and need someone to hold their hands and give them the opportunity to express their talents. For this we need to activate the governmental decisions to support them and integrate them into the social order and in regular classrooms, and we should help these children to open doors to integrate them into the kindergartens, schools to show their hidden potentials whether the scientific or the practical to be added to the social balance and not a burden not to run away from (Mohammad Ben abdallah Al Husseini, 2007).

\subsection{Importance of This Study}

The lack of integration of the physically disabled children in regular classrooms consequent 
negative effects, as isolating physically disabled child leads to the denial of the features that can be obtained if left to live among his ordinary colleagues. Isolating physically disabled students leads to a sense of separation from society generates non-belonging and a sense of rejection of everything around them. Thus turns the physically disabled child to helpless human and a burden on all his family and society, unconfident of people around him and generating negative attitudes towards society.

The presence of a disabled child with normal children in regular schools, have a greater impact on the growth of academic, emotional, and social development of physically disabled child through the role of the nature of the social studies requirements in case the physically disabled child succeed in facing,increase self-confidence and the confidence of the others, and working on the development of his motives and expectations for himself and the expectations of others.

The presence of the physically disabled child in a regular school contributes to raise the morale of parents and thus increases the expectations and positive attitudes toward their children, and help disabled students themselves to overcome the psychological problems they may face and to overcome the feeling of shyness as well.

\subsection{Statement of the Study}

The presence of a disabled child in the family does not mean surrender to this disability and isolate the child from society.On the contrary, it is the duty of the family to integrate this physically disabled child in the family with his brothers first and then integrate it with their peers in regulars classrooms, and this helped him to overcome psychological, emotional,and social problems which may face.Parents who have a physically disabled child or more to learn the extent of their way to incorporate a larger role falls to the parents; therefore, attention must be paid to predispose them first to deal with this disabled child and holds parents different directions vary from guardian to another about having a physically disabled child in his family and about the possibility of integrating them in normal classes.From here, the researcher decided to study the viewpoint of parents about the integration process through the distribution of their children's questionnaire in regular classes.

\subsection{The Purpose of the Study}

This study aimed to find out the challenges facing parents in the integration of physically disabled child in regular classes, and also to study the effect of educational level, gender, and the standard of living for the parents to their point of view.

\subsection{Questions of the Study}

1. What are the challenges facing the integration of disabled children in regular classrooms from the perspective of their parents?

2. Is there a statistically significant difference in the point of view of parents toward integration of physically disabled child in regular classes due to the educational level (high school or less, Bachelor's degree or higher)? 
3. Is there a statistically significant difference in the point of view of parents towards integration of physically disabled child in regular classes due to gender (Male, Female)?

4. Is there a statistically significant difference in the point of view of the parents towards the integration of physically disabled child in regular classes due to the level of living of the parents (high, medium)?

\subsection{Procedural Definitions}

\subsubsection{Physical disability}

It is known as disorder and sensory defect that prevent an individual from using his body to carry out normal functions of everyday life.

\subsubsection{Integration}

Integration is to provide opportunities for physically disabled children to engage in the public education system as a measure to emphasize the principle of equal opportunities.In education, it aimed at the integration in general to face the special educational needs of the child physically disabled within the framework of a regular school.According to the methods, approaches,appropriate educational methods of study, and oversees the submission a specialized education; in addition, to a team of education in the public school.

\subsection{Determinants of the Study}

This study specific to parents who have a physically disabled child or more in Irbid Governorate and any similar sample, which is also specific variables that have been studied and is the educational level of the parents, the gender and the standard of living for them.

\section{Previous Studies}

Many researchers conducted studies to find out the challenges faced by students with disabilities when they integrate in regular classes and the perspective of parents and educators about this integration. The researcher will review some of these as examples.

Al Bustanji (2002) conducted a study that aimed to identify the level of social interactions for students with learning difficulties with ordinary students in regular schools in Amman according to variable of gender, nature of school in terms of mixing, grade level, type of learning difficulties faced by students with learning difficulties, and the number of years a student enrollment difficulty in chamber of sources. The result indicated the presence of interactions between ordinary students and students with learning difficulties. As the result indicated, students with learning difficulties from the fifth grade level to have social interactions with ordinary students more positive than the second grade level. The result also indicated that students with mixed learning difficulties have social interactions with ordinary students in regular schools are less positive than those of students with reading difficulties. Results did not show statistically significant differences in social interactions for students in regular schools depending on the variables of gender, nature of the school in terms of mixing 
and years of student enrollment with learning difficulties in chamber of sources.

Abdu-Jabar \& Massoud (2002) held a study aimed to explore the views of managers and teachers of ordinary and special education teachers to integrate students with disabilities in regular schools and identify the impact of variables occupation, scientific degree, the category of disability and the type of program on the views of managers and teachers. The sample of the study included principals and teachers who work in regular schools thereto programs for the integration in the region of Al-Riyadh in Saudi Arabia. The managers and teachers answered the questionnaire of the study that consisted of four dimensions: the impact of the integration in the views of managers and teachers, accepting students with disabilities, modify negative behavior and the willingness and cooperation of teachers. The results showed an agreement of both managers and special education teachers and regular education teachers on the existence of a positive impact of integration programs. The study also found that there are statistically significant differences in views on integration programs in regular schools due to the variables of occupation, scientific degree, category of disability and the type of program of integration.

Al-Qahtani (2003) tried to assess trends in the primary school teachers towards the integration of individuals with visual disability in the primary school in Al-Riyadh in Saudi Arabia with their normal peers. The study sample consisted of teachers. The results indicated the presence of statistically significant differences between teachers due to the variable age for the younger ages and ranging between (20-30) years; whereas, the results did not show the presence of statistically significant differences between teachers attributed to the experience. Also the results confirmed that it can integrate blind individuals within the public schools with their normal peers and this is because the teachers' positive trends toward integration of blind individuals.

Yousef (2005) conducted another study discussing the extent of the difficulties facing special education teachers in their work, and the extent of the effect of some variables related to them in the area identified for these difficulties. The sample of the study consisted of teachers (males, females) and showed average total score in terms of the difficulties and showed a lack of significant difference attributed to the variables of scientific qualification, the role of the teacher, the interaction between them, the interaction between academic qualification, the role of the teacher,and the years of experience. Also the study showed the presence of significant difference attributed to the variable years of experience at least 7 years, the interaction between academic qualification, and years of experience. Moreover, the results showed that the order of the difficulties faced by special education teachers according to their importance associated with difficulties related to the student ranked first, followed by the educational environment ,teaching technique, management then the family, and finally the teacher in fifth place. As for the variable curriculum, it had no effect and showed a lack of statistically significant difference attributed to a variable of type of disability (hearing, visual, mental and physical) of the difficulties faced by special education teachers in their work.

Abu Jalaleh (2009) conducted analytical study of scientific studies and working papers that provide the application programs for integration project in a number of countries in the world, 
and the law of the United Nations and UNESCO, forums and symposiums and recommendations made in conferences private with special needs about the trend towards integrating people with special needs in educational institutions (practices and challenges), the study found several results was the most important: that all countries of the world recognizes the need for the application of the integration program in the various stages of education because of its positive effects on the psychology student with a disability and psychological guardian, that the integration gives students with disabilities the right to education, The integration is a leap advanced quality care of humanitarian aspects.

\section{Methodology of the Study}

\subsection{Population of the Study}

The population of the study consisted of all the parents of disabled children in the Governorate of Amman, and their total number (12540) guardian.

\subsection{Sample of the Study}

The sample of the study consisted of (196) guardian for physically disabled children in the Governorate of Amman, representing the population of the study.

\subsection{Tool of the Study}

After the researcher reviewed number of previous studies on the challenges facing the integration of physically disabled in regular classes from the viewpoint of their parents and the tools used, a special questionnaire was developed for measuring the viewpoint of the parents of the challenges facing the integration of their physically disabled children in regular classrooms. The questionnaire consisted in the final from of (20) items and has been designed to respond to the questionnaire based on Likert quadrant scale. The study included a number of variables such as the educational level (high school or less, Bachelor degree or higher), the gender of the parent (male, female), and the standard of living for parents (high, medium).

\subsection{Validity of the Test}

To check the validity of the questionnaire, the researcher applied the study on an exploratory sample consisting of (25) guardians were excluded from sample of the study in centers where the study has been applied and for the period of two weeks between the first distribution of the questionnaire and the second time so as to minimize the impact of views. The validity of the tool had been calculated by using correlation coefficient Cronbach's alpha and found 0.89 and this is considered appropriate to conduct such a study.

\subsection{Procedures of the Study}

This study has been applied throughout one month. A questionnaire was distributed to measure the challenges facing the integration of physically disabled children in regular classrooms among (196) guardians. Then the researcher collected the questionnaires, data and then this data were analyzed statistically using the Statistical Packages for Social Sciences (SPSS). 


\subsection{Statistical Treatment}

In order to process the data, results were analyzed for each paragraph in the questionnaire separately using the means and standard deviations. The t-test is used to examine questions related to variables educational level, gender, standard of living for the parents and the graphic representation of the independent variables.

\section{Results of the Study}

This study aimed to find out the challenges facing the integration of physically disabled child in regular classrooms from the viewpoint of their parents, and also aimed to determine the impact of educational level, gender, and the standard of living of the parents on their views.

To answer the first question related to challenges facing the integration of physically disabled children in regular classrooms: What are the challenges facing the integration of physically disabled children in regular classrooms from the perspective of their parents? A questionnaire was distributed among parents then calculating the mathematical means and standard deviations. Table no. 1 shows the results.

Table 1. Challenges facing the integration of physically disabled children in regular classrooms

\begin{tabular}{lcc}
\hline & Mathematical means & Standard deviation \\
\hline Paragraph 1 & 4.14 & 0.846 \\
Paragraph 2 & 4.19 & 0.857 \\
Paragraph 3 & 3.19 & 1.072 \\
Paragraph 4 & 3.21 & 0.978 \\
Paragraph 5 & 4.14 & 0.898 \\
Paragraph 6 & 3.17 & 1.217 \\
Paragraph 7 & 3.26 & 1.211 \\
Paragraph 8 & 4.19 & 1.029 \\
Paragraph 9 & 3.21 & 1.320 \\
Paragraph 10 & 4.06 & 0.989 \\
Paragraph 11 & 4.54 & 0.777 \\
Paragraph 12 & 2.89 & 1.202 \\
Paragraph 13 & 3.63 & 1.294 \\
Paragraph 14 & 2.89 & 0.942 \\
Paragraph 15 & 4.00 & 1.087 \\
Paragraph 16 & 4.39 & 0.859 \\
Paragraph 17 & 3.44 & 1.219 \\
Paragraph 18 & 2.98 & 1.024 \\
Paragraph 19 & 4.15 & 0.877 \\
Paragraph 20 & 4.34 & 0.823 \\
Total & 3.70 & 0.190 \\
\hline
\end{tabular}




\section{Mll Macrothink}

International Journal of Education

ISSN 1948-5476

2017, Vol. 9, No. 1

Table 1 shows that there are statistically significant differences in the views of parents about the challenges facing the integration of physically disabled child in regular classes, and shows the results of questionnaire that has been distributed to the (196) guardians. Themathematical means and standard deviation were calculated and the results showed that the question 11 received highest arithmetic means a (4.54), while the next arithmetic means was for question no. 16 (4.39).

The standard deviation of question no. 11 was $(0.777)$ which is higher than $(\alpha \leq, 05)$, and this means it is statically significant. The standard deviation of the question no. 16 which was almost similar (0.859) and is also considered statistically significant.

Graph 1: Challenges facing the integration of physically disabled children in regular classrooms from the perspective of their parents.

It seems clear from the graph that the arithmetic means of question no. 11 had the highest means and follows question no. 16 then (1, 2, 5, 7 and 19) were almost similar which means that the views of parents about challenges facing the integration of their physically disabled child in regular classroom were positive.

To answer the second question about the views of the parents and the educational level: Is there a statistically significant difference in the point of view of parents towards integration of physically disabled child in regular classes due to the educational level (high school or less, Bachelor's degree or higher?) The arithmetic means and standard deviation were calculated and table 2 shows the results.

Table 2. The arithmetic means and standard deviations and t-test variable depending on the educational level of the parents

\begin{tabular}{|c|c|c|c|c|c|c|c|}
\hline & $\begin{array}{l}\text { Level of } \\
\text { education }\end{array}$ & Number & $\begin{array}{l}\text { Arithmetic } \\
\text { means }\end{array}$ & $\begin{array}{l}\text { Standard } \\
\text { deviation }\end{array}$ & t-test & $\begin{array}{l}\text { Degree } \\
\text { of } \\
\text { freedom }\end{array}$ & $\begin{array}{l}\text { Statistical } \\
\text { significance }\end{array}$ \\
\hline \multirow[t]{2}{*}{$\begin{array}{l}\text { Views } \\
\text { of } \\
\text { parent }\end{array}$} & $\begin{array}{l}\text { High } \\
\text { school or } \\
\text { less }\end{array}$ & 90 & 3.74 & 0.203 & 4.152 & 264 & 0.000 \\
\hline & $\begin{array}{l}\text { Bachelor } \\
\text { or more }\end{array}$ & 106 & & & & & \\
\hline
\end{tabular}

Table 2 shows the presence of statistically significant attributed to the educational level of the parents. The results of the questionnaire, which was distributed to 196 guardians about their views about the challenges facing the integration of their child physically disabled in regular classrooms, arithmetic means and standard deviations were calculated and the results showed that parents who have their level of education high school or less got the averages higher than the parents who have their level of education bachelor degree or higher were as follows: (3.74 and 3.65), respectively, and this means that the educational level of the parents has an impact 
on their views.

It is clear from these results that whenever the educational level of the parents was the highest point of view about the challenges facing the integration more positive.

The standard deviation for the parents with educational level high school or less was $(0.203)$ the highest of $(\alpha \leq 0,05)$ that means it is statistically significant. The standard deviation for the parents who have bachelor degree or higher level of education was lower (0.160) which is also statistically significant. So table 2 shows the presence of statistically significant differences attributed to the educational level of the parents in favor of high school or less.

To answer the third question about the point of view of the parents about the challenges facing the integration of physically disabled child in regular classrooms: Is there a statistically significant differences in the point of view of parents towards integration of physically disabled child in regular classrooms according to gender (male, female)? The arithmetic means and standard deviations were calculated and table 3 shows the results.

Table 3. The arithmetic means and the standard deviations and t-test depending on the variable of gender

\begin{tabular}{llllllll}
\hline & Gender & Number & $\begin{array}{l}\text { Arithmetic } \\
\text { means }\end{array}$ & $\begin{array}{l}\text { Standard } \\
\text { deviations }\end{array}$ & T-test & $\begin{array}{l}\text { Degree of } \\
\text { freedom }\end{array}$ & $\begin{array}{l}\text { Statistical } \\
\text { significance }\end{array}$ \\
\hline $\begin{array}{l}\text { Parents } \\
\text { point of } \\
\text { view }\end{array}$ & Male & & & 0.152 & $7.329-$ & 264 & 0.000 \\
& & & & & & \\
\hline & Female & & & 0.188 & 3.77 & 107 & \\
\hline
\end{tabular}

Table 3 shows the presence of statistically significant differences $(\alpha \leq 0.05)$ attributed to gender differences and came in favor of females.

Table 3 shows that there are statistically significant differences due to the variable gender. The results of the questionnaire which was distributed among 196 guardians about their point of view about the challenges facing the integration of their physically disabled child in regular classrooms, the arithmetic means and the standard deviation were calculated and the results showed that male guardian got means less than females as follows :( 3.61 and 3.77), respectively this means that gender has an impact on the views of parents.

The standard deviation for the male guardians was (0.152) which is higher than $(\alpha \leq 0.05)$, which means that statistically significant. The standard deviations of the parents were female (0.188) which is also statistically significant. So, table 3 shows the presence of statistically significant differences due to the variable of gender in favor of females.

To answer the fourth question about the impact of the standard of living of the parents on their views : Is there a statistically significant difference in the point of the parents towards the integration of physically disabled child in regular classes due to the level of living of the 
parents (high, medium)? The arithmetic means and the standard deviation and table 4 show the results.

Table 4. Shows the arithmetic means and the standard deviations, T-test depending on the variable standard of living

\begin{tabular}{llllllll}
\hline & $\begin{array}{l}\text { Standard } \\
\text { of living }\end{array}$ & Number & $\begin{array}{l}\text { Arithmetic } \\
\text { means }\end{array}$ & $\begin{array}{l}\text { Standard } \\
\text { deviation }\end{array}$ & T-test & $\begin{array}{l}\text { Degree of } \\
\text { freedom }\end{array}$ & $\begin{array}{l}\text { Statistical } \\
\text { significance }\end{array}$ \\
\hline $\begin{array}{l}\text { Parents } \\
\text { point of }\end{array}$ & High & 136 & 3.74 & 0.201 & 5.730 & 264 & 0.000 \\
view & & & & & & & \\
& Medium & 60 & 3.61 & 0.123 & & & \\
\hline
\end{tabular}

We can see from table (4) the presence of statistically significant differences $(\alpha \leq 0.05)$ attributed to the level of living and differences came to the benefit of parents with high incomes.

Table 4 shows the presence of statistically significant differences due to the variable standard of living. The results of the questionnaire, which was distributed among 196 guardians about their point of views of the challenges facing the integration of their physically disabled child in regular classrooms, the arithmetic means and the standard deviations, were calculated and the results showed that parents with medium income had lower means than parents with high income they were (3.74 and 3.61), respectively, and this indicates that the standard of living has and impact on the views of parents where that is no doubt that the standard of living affect highly on the lives of the individuals and their attitudes.

The standard deviation for parents with high income was $(0.201)$ which is higher than $(\alpha \leq 0$, 05 ) this means that it is statistically significant. The standard deviation of the parents with medium income $(0.123)$ which is also statically significant then, table 4 shows the presence of statistically significant differences attributable to the level of living and for the benefit of parents with high income.

\subsection{Conclusion}

The presence of a physically disabled child in the family no doubt requires parental effort and greater responsibilities, and with no doubt also the parents should try to integrate their physically disabled child in the society in general and in school in particular. Parents should accept their child as he is and be patient with him and be with him as companions and should not be watching any bad behavior by him as long as has not happened yet, but instead watching his good behaviors and praise him. The practice of talking and dialogue with this type of children even in the case of his inability to reply or response is stammered is no doubt gives him the opportunity to respond or to express the way in which it is estimated. It is very important not to distinguish between him and the rest of his brothers who do not suffer a disability and try to develop skills, sensory, and intellectual following the "Montessori" way 
because it is very positive and has proven to encourage the physically disabled child to be confident in his abilities. Also to be confident in himself because it is an important and reflexive matter, attempt to integrate the child to play with his brothers, help him to indulge in community, and overcome the barrier of shame, fear, and more importantly is to integrate into regular classes.

\subsection{Recommendations of the Study}

In light of the findings of the current study, the researcher suggested the following recommendations:

1- Hold some seminars and workshops to educate parents of the importance of the integration of physically disabled child in regular classrooms and help them overcome the barrier of shame.

2- Conduct further studies on a wider sample to include a larger number of parents and other governorates in Jordan and not only Amman.

3- Study other variables and their impact on the attitudes of parents towards integration of physically disabled child in regular classes.

\section{References}

Abdul Jabbar, Abdul Aziz Masood, Wael. (2002). Survey of the views of managers and teachers in regular schools about integration programs, Research Center College of Education, King Saud University, Saudi Arabia.

Abu Jalaleh, S. (2009). Attitudes towards integrating people with special needs in education institutions, (practices and challenges). Journal of Education, Qatar National Commission for Education, Culture and Science, 168, 94-119.

Al-bustanji, Murad. (2002). social interactions for students with learning difficulties with ordinary students in regular schools in Amman. Unpublished MA Thesis, Amman-Jordan.

Al-Qahtani, Abdullah. (2003). Trends of primary teachers to integrate blind students at the elementary level in the city of Al-Riyadh with their normal peers. Unpublished MA Thesis, University of Jordan, Amman-Jordan.

Al-Shakhs, Abdulaziz (2004). The evolution of the perception of children with special needs and methods of care, psychological counseling magazine, GS8, Ain Shams University, pp. 175-199.

Educational Studies Center, CARE, (2000). Proceedings of the school day, Palestinian\& Israeli educational curricula, Jerusalem.

Mohammad bin Abdullah Al-Husseini. (2007). "Special needs....basic strategy "Al-Yamamah Press Foundation, Al-Riyadh 0.1 in May, no. 14190. 


\section{Macrothink}

Waheed Al-Sayed Hafith (2001). "Building a curriculum in the Arabic language for students in the vocational section in the Intellectual Education School", unpublished Ph.D thesis, Faculty of Education - Zaqaziq University, Banha Branch.

Yousef, Talal. (2005). Special Education in the care of people with special needs, Dar Osama for Publishing and Distribution, Amman-Jordan.

\section{Copyright Disclaimer}

Copyright for this article is retained by the author(s), with first publication rights granted to the journal.

This is an open-access article distributed under the terms and conditions of the Creative Commons Attribution license (http://creativecommons.org/licenses/by/3.0/). 